\title{
Chromosome Analysis in Couples with Recurrent Abortions
}

\author{
Kan-Ichi Soh, Akira Yajima, Nobuyoshi Ozawa, Yoichi \\ Abe, Toshifumi Takabayashi, Shinji Sato, Soujin Sou \\ and Masakuni Suzuki
}

Department of Obstetrics and Gynecology, Tohoku University School of Medicine, Sendai 980

\begin{abstract}
Soh, K., Yajima, A., Ozawa, N., Abe, Y., Takabayashi, T., Sato, S., Sou, S. and Suzuki, M. Chromosome Analysis in Couples with Recurrent Abortions. Tohoku J. exp. Med., 1984, 144 (2), 151-163-Chromosome analysis using a G-Banding technique was performed in 35 couples (70 individuals) with a history of two or more spontaneous abortions of unknown cause. Among these individuals, $5(7 \%)$ showed balanced translocations, all of whom were female. The outcome of 31 pregnancies of 10 balanced translocation carriers was as follows : Ten of the offspring had normal phenotypes $(32 \%), 5(16 \%)$ were born with chromosomal abnormalities and $16(52 \%)$ were spontaneously aborted. recurrent abortions; chromosome aberration; translocation carrier ; amniocentesis
\end{abstract}

Spontaneous abortions account for $15-20 \%$ of the total number of clinically verified pregnancies, so that the frequency of abortions including cases in which abnormal fertilized ova fail to become implanted at the time of implantation is undoubtedly much higher. The cause of spontaneous abortion during the first trimester of pregnancy is often uncertain, but a recent study has indicated that some $50 \%$ of spontaneously aborted fetuses have chromosomal abnormalities (Kajii 1979). The majority of such abnormalities, which arise at the stage of gamete development or fertilized ova cleavage, are either cases of chromosomal nondisjunction or mutation and, consequently, the recurrence of such abnormalities is unlikely. In a very small percentage, however, it is thought that the gamete has the same chromosomal abnormality as that of one of the parents. In such a case, it often occurs that an unbalanced gamete is produced repeatedly, which may result in the recurrence of spontaneous abortions.

It is known that the most common chromosomal abnormality of parents of normal phenotypes is the so-called balanced translocation and it has been reported that such translocation carriers account for $0.3 \%$ of the normal population (Jacobs et al. 1972).

Received for publication, February 1, 1984. 
In recent years, several studies of the incidence of translocation carriers among couples experiencing recurrent spontaneous abortions have been made, but there has been little agreement on the actual incidence. Genest (1979) reported an incidence of $0 \%$ among 102 subjects, whereas Wisniewski et al. (1980) have reported the highest incidence of $50 \%$ among 12 subjects. The present paper reports the incidence of translocation carriers among couples experiencing either recurrent abortions or birth of offspring with congenital abnormalities, and the outcome of pregnancies of translocation carriers.

\section{Methods}

\section{Chromosome analysis of peripheral lymphocytes}

Peripheral venous blood was obtained with a heparin-treated injection syringe from the parents of children with congenital anomalies or the couples experiencing recurrent abortions. RPMI 1640 supplemented with $20 \%$ fetal bovine serum (GIBCO) and $100 \mu \mathrm{g} / \mathrm{ml}$ $\mathrm{AB}-\mathrm{PC}$ was used for the culture of the lymphocytes. Two $\mathrm{ml}$ of this medium was added to sterilized plastic tubes together with $0.05 \mathrm{ml}$ of PHA (phytohemagglutin M-form). To this solution was dripped $0.1 \mathrm{ml}$ of the sample blood and, after thorough mixing, the solution was kept for culture in a $37^{\circ} \mathrm{C}$ container containing $5 \% \mathrm{CO}_{2}$. After $70 \mathrm{hr}$ of culture, colcemid was added to obtain a final concentration of $0.2 \mu \mathrm{g} / \mathrm{ml}$ and further $2 \mathrm{hr}$ of culture then allowed.

The cultured cells were then centrifuged at 1,000 rpm for 5 min. After adding $4 \mathrm{ml}$ of a hypotonic $0.075 \mathrm{M} \mathrm{KCl}$ solution to the sedimentated cells, careful pipetting was performed and the solution allowed to rest for 7-10 min. Again 5 min of centrifugation at 1,000 rpm was done and the supernatant was discarded. After careful stirring and attaining a floating state, $4 \mathrm{ml}$ of the previously cooled Carnoy fixative solution (methanol to acetic acid in a ratio of $3: 1$ ) were added along the sides of the test tube and again the solution was left to mix well. Fixation entailed washing the sediment thrice for over $30 \mathrm{~min}$. The supernatant was again discarded and 2 or 3 drops of the solution were put on a slide glass and dried in several seconds using a dryer.

The prepared samples were dried at room temperature for about 7 days and then treated at $37^{\circ} \mathrm{C}$ for about $30 \mathrm{sec}$ in $0.05 \%$ trypsin-Hanks solution. They were then rapidly washed in $0.2 \%$ EDTA and distilled water and again dried. Finally, they were stained for $20 \mathrm{~min}$ in $2 \%$ buffered Giemsa solution ( $\mathrm{pH} 6.8$ ).

Under a microscope, the chromosome number was determined from more than 20 cells and the karyotype of the chromosomes was analyzed in photomicrographs.

\section{Culture of amniotic fluid and chromosome analysis of fetal cells}

In cases that either the patient or her husband was a balanced translocation carrier, the amniotic fluid was sampled from the abdominal region between the 16th and 20th weeks of pregnancy of the patient. F-10 (GIBCO) supplemented with $20 \%$ fetal bovine serum (GIBCO) and $100 \mu \mathrm{g} / \mathrm{ml} \mathrm{AB-PC}$ was used as the culture medium. Three $\mathrm{ml}$ of amniotic fluid were placed in Nunc plastic dishes with $3 \mathrm{ml}$ of the culture medium. This solution was left to culture in a $37^{\circ} \mathrm{C}$ container holding $5 \% \mathrm{CO}_{2}$ for one week. One half of the culture medium was then replaced, and thereafter one half was replaced every three days.

After sufficient proliferation of fibroblasts, colcemid (at a final concentration of $0.3 \mu \mathrm{g}$ / $\mathrm{ml}$ ) was added and 4-6 hr of further culture allowed. The cells were then washed twice in Puck's saline A solution and detached from the culture dish using $0.05 \%$ trypsin EDTA solution (GIBCO). After 5 min of sedimentation at $800 \mathrm{rpm}$, the supernatant was discarded and the cells treated with a $0.075 \mathrm{M} \mathrm{KCl}$ hypotonic solution for 10-15 min. Fixation, sample preparation, staining and microscopy were performed as described for blood samples. 
TABLE 1. Chromosome studies in couples with recurrent spontaneous abortions

\begin{tabular}{cccc}
\hline $\begin{array}{c}\text { Number of } \\
\text { abortions }\end{array}$ & $\begin{array}{c}\text { Couple(s) with no } \\
\text { normal liveborn } \\
\text { offspring }\end{array}$ & $\begin{array}{c}\text { Couple(s) with } \\
\text { normal liveborn } \\
\text { offspring }\end{array}$ & Total \\
\hline 2 & 13 & 1 & 14 \\
3 & 14 & 2 & 16 \\
4 & 2 & 1 & 3 \\
5 & 1 & 0 & 1 \\
8 & 1 & 0 & 1 \\
Total & 31 & 4 & 35 \\
\hline
\end{tabular}

TABLE 2. Translocation carriers among patients with recurrent spontaneous abortions

\begin{tabular}{cccc}
\hline Case No. & $\begin{array}{c}\text { Translocation } \\
\text { type }\end{array}$ & Karyotype & $\begin{array}{c}\text { Number of } \\
\text { abortions }\end{array}$ \\
\hline 1 & rob. (D/D) & $45, \mathrm{XX},-13,-14,+\mathrm{t}(13 \mathrm{q} 14 \mathrm{q})$ & 2 \\
2 & rob. (D/G) & $45, \mathrm{XX},-13,-22,+\mathrm{t}(13 \mathrm{q} 22 \mathrm{q})$ & 2 \\
3 & rob. (D/G) & $45, \mathrm{XX},-14,-21,+\mathrm{t}(14 \mathrm{q} 21 \mathrm{q})$ & 5 \\
4 & rob. (G/G) & $45, \mathrm{XX},-21,-21,+\mathrm{t}(21 \mathrm{q} 21 \mathrm{q})$ & 3 \\
5 & rcp. (D/D) & $46, \mathrm{XX}, \mathrm{t}(14 ; 15)(\mathrm{q} 24 ; \mathrm{q} 24)$ & 3 \\
\hline
\end{tabular}

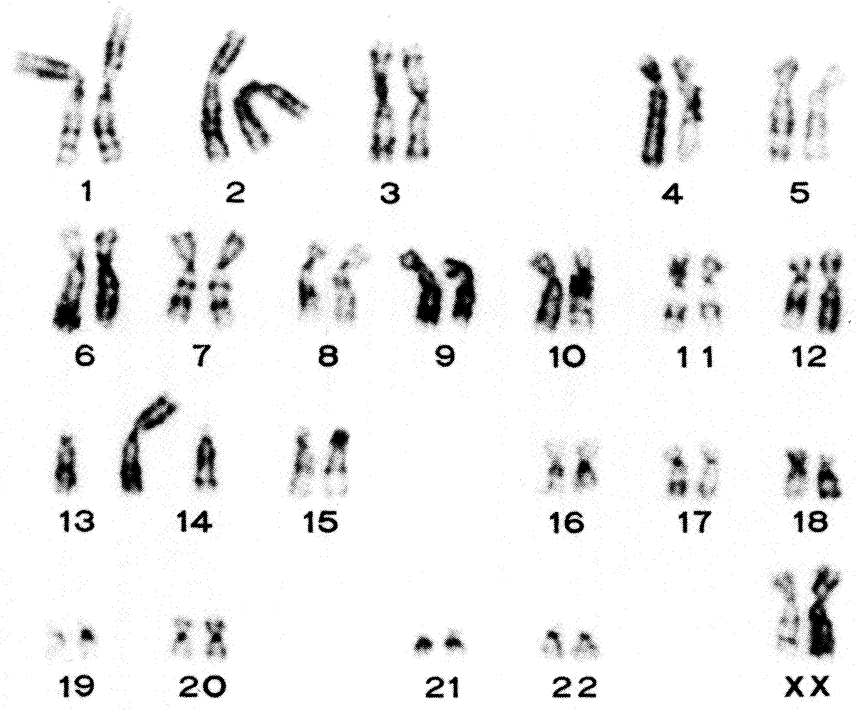

Fig. 1. Karyotype of Case 1.

$45, \mathrm{XX},-13,-14,+\mathrm{t}(13 \mathrm{q} 14 \mathrm{q})$ 


\section{Results}

The incidence of translocation carriers among couples experiencing recurrent abortions

Chromosome analysis was performed in 35 couples (70 individuals) with a

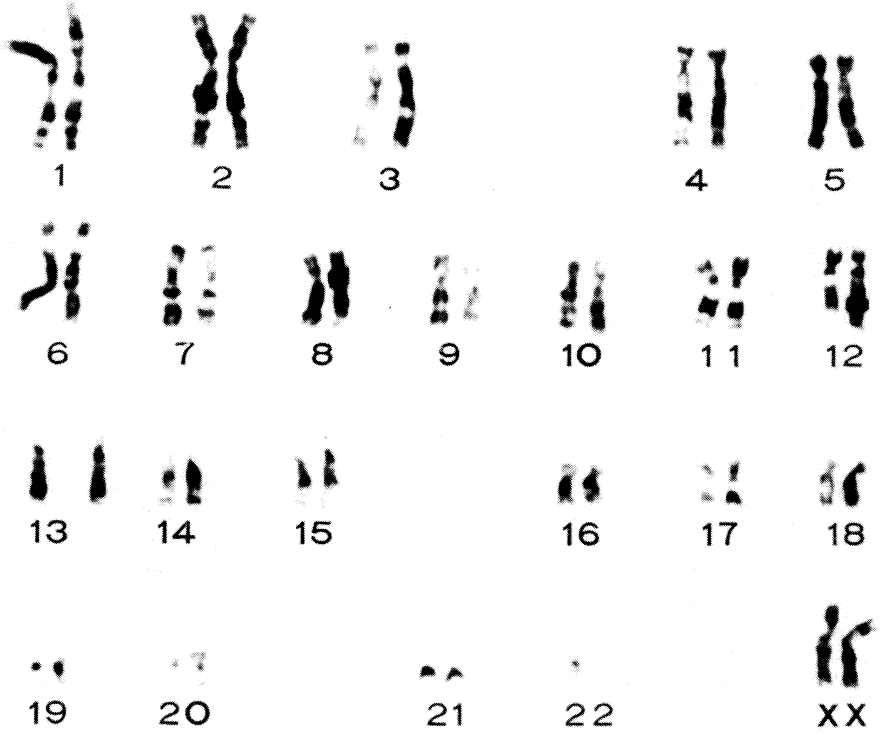

Fig. 2. Karyotype of Case 2.

$45, \mathrm{XX},-13,-22,+\mathrm{t}(13 \mathrm{q} 22 \mathrm{q})$

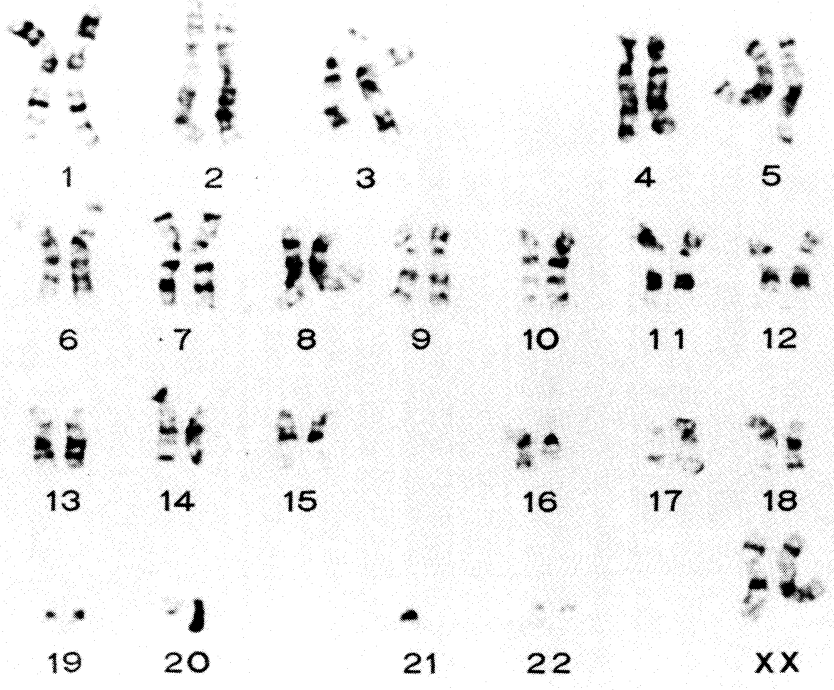

Fig. 3. Karyotype of Case 3.

$45, \mathrm{XX},-14,-21,+\mathrm{t}(14 \mathrm{q} 21 \mathrm{q})$ 
history of two or more spontaneous abortions of unknown cause (Table 1). Among these individuals, 5 showed balanced translocations (Table 2), all of whom were female. There were four cases of Robertsonian translocation; that is, Case 1, t (13q14q) (Fig. 1), Case 2, t (13q22q) (Fig. 2), Case 3, t (14q21q) (Fig. 3), Case
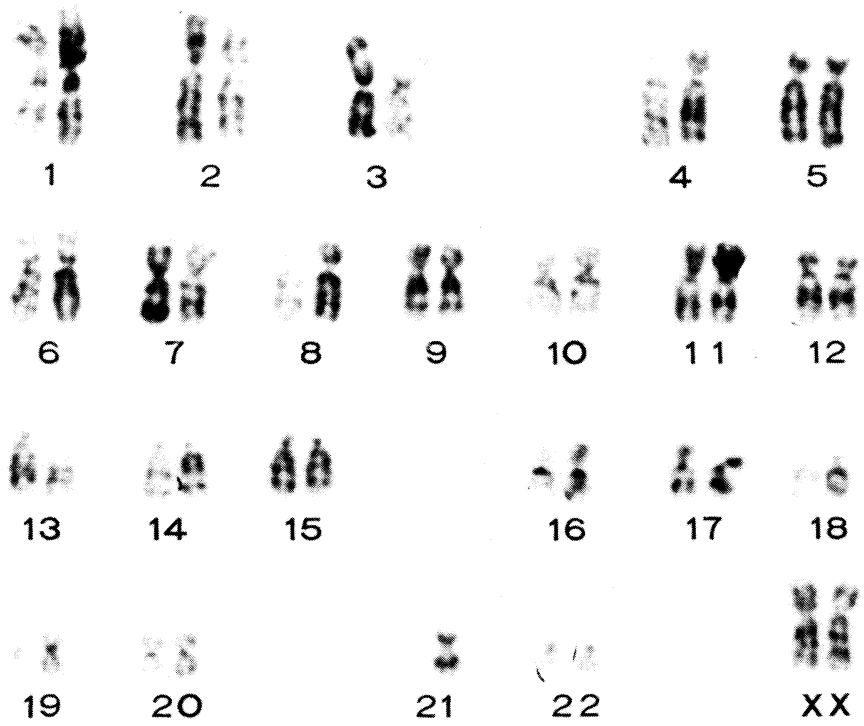

Fig. 4. Karyotype of Case 4.

$45, \mathrm{XX},-21,-21,+\mathrm{t}(21 \mathrm{q} 21 \mathrm{q})$
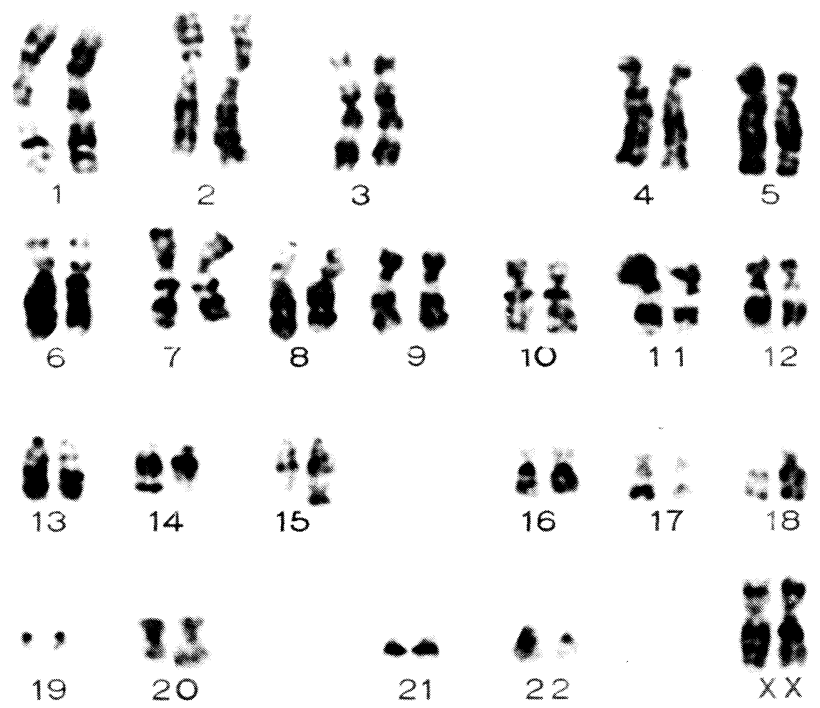

Fig. 5. Karyotype of Case 5. $46, \mathrm{XX}, \mathrm{t}(14 ; 15)(\mathrm{q} 24 ; \mathrm{q} 24)$ 
TABLE 3. Frequencies of chromosome abnormalities among couples with recurrent spontaneous abortions

\begin{tabular}{cccc}
\hline $\begin{array}{c}\text { Number of } \\
\text { abortions }\end{array}$ & $\begin{array}{c}\text { Robertsonian } \\
\text { translocation } \\
\text { (couples) }\end{array}$ & $\begin{array}{c}\text { Reciprocal } \\
\text { translocation } \\
\text { (couples) }\end{array}$ & $\begin{array}{c}\text { Total } \\
(\%)\end{array}$ \\
\hline 2 & $2 / 14$ & $0 / 14$ & $2 / 14(14)$ \\
3 & $1 / 16$ & $1 / 16$ & $2 / 16(13)$ \\
4 & $0 / 3$ & $0 / 3$ & $0 / 3(0)$ \\
5 & $1 / 1$ & $0 / 1$ & $1 / 1(100)$ \\
8 & $0 / 1$ & $0 / 1$ & $0 / 1(0)$ \\
Total & $4 / 35$ & $1 / 35$ & $5 / 35(14)$ \\
\hline
\end{tabular}

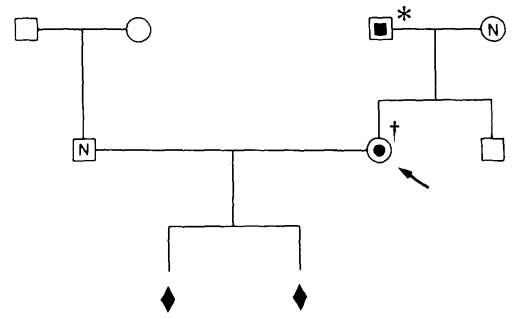
[N (N) Normal karyotype
$\square \bigcirc$ Not examined
[- Balanced translocation
$\checkmark$ Abortion
- Unbalanced

Fig. 6. Pedigree of Case 1

* 45, XY, $-13,-14,+\mathrm{t}(13 \mathrm{q} 14 \mathrm{q})$ (Case 6)

$\dagger 45, \mathrm{XX},-13,-14,+\mathrm{t}(13 \mathrm{q} 14 \mathrm{q})($ Case 1$)$
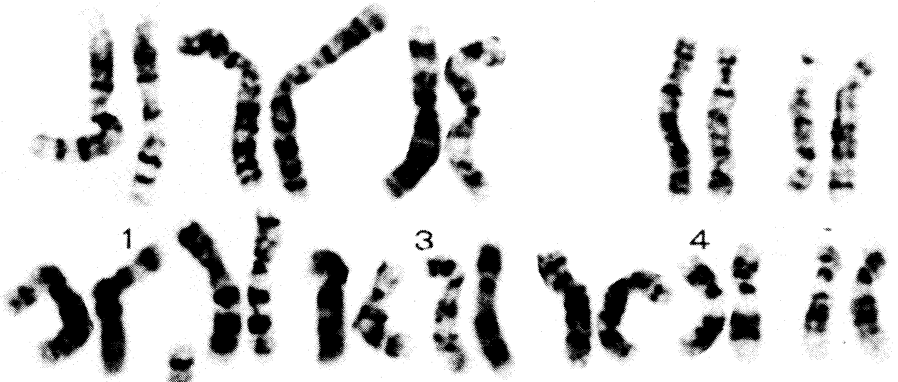

6

7

8

9

10

$11 \quad 12$

Q

812

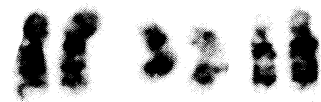

13

14

15

16

17

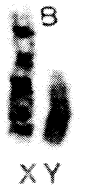

1920

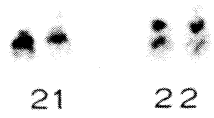

Fig. 7. Karyotype of Case 6.

$45, \mathrm{XY},-13,-14,+\mathrm{t}(13 \mathrm{q} 14 \mathrm{q})$ 
4, $\mathrm{t}(21 \mathrm{q} 21 \mathrm{q})$ (Fig. 4). The other one case was reciprocal translocation; Case $5, \mathrm{t}$ $(14 ; 15)$ (q24; q24) (Fig. 5). In other words, the incidence among these 35 couples was $14 \%(5 / 35)$ - all 5 of the carriers being female.

Pedigree studies of the carriers

Pedigree study was possible in 2 of the 5 translocation carriers, Cases 1 and 5 of Table 2. As shown in Fig. 6, it was found that the father of Case 1 (that is, Case 6) was a translocation carrier of the same kind (Fig. 7). Pedigree study of Case 5 (Fig. 8) showed that the father (Case 7) had balanced translocation (Fig. 9), the younger brother had a normal karyotype and the younger sister had an unbalanced translocation.

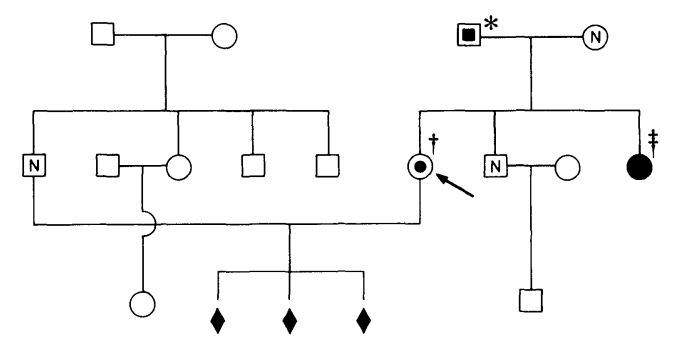

Fig. 8. Pedigree of Case 5.

* 46, XY, t (14; 15) (q24; q24) (Case 7)

$\dagger 46, \mathrm{XX}, \mathrm{t}(14 ; 15)(\mathrm{q} 24 ; \mathrm{q} 24)$ (Case 5$)$

$\ddagger 46, \mathrm{XX}$, der $(15), \mathrm{t}(14 ; 15)(\mathrm{q} 24 ; \mathrm{q} 24)$ pat

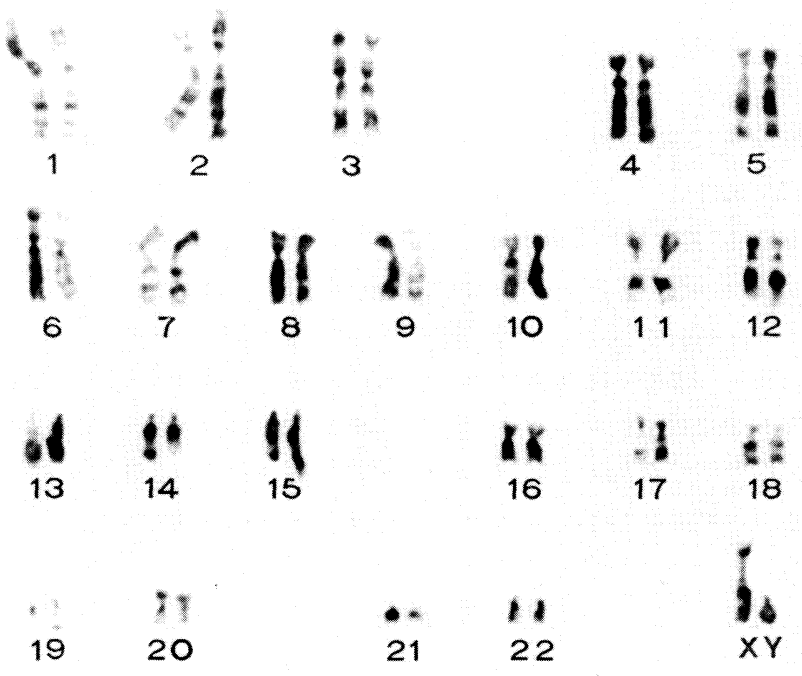

Fig. 9. Karyotype of Case 7. $46, \mathrm{XY}, \mathrm{t}(14 ; 15)(\mathrm{q} 24 ; \mathrm{q} 24)$ 
Table 4. Parental chromosome studies in three cases of chromosome abnormalities

\begin{tabular}{ccc}
\hline Child karyotype & Father karyotype & Mother karyotype \\
\hline $\begin{array}{c}47, \mathrm{XX},+18, \mathrm{t}(5 ; 18) \\
(\mathrm{q} 15 ; \mathrm{q} 22)\end{array}$ & $\begin{array}{c}46, \mathrm{XY}, \mathrm{t}(5 ; 18) \\
(\mathrm{q} 15 ; \mathrm{q} 22) \quad(\text { Case } 8)\end{array}$ & $46, \mathrm{XX}$ \\
$47, \mathrm{XY},+21, \mathrm{t}(5 ; 12)$ & $46, \mathrm{XY}$ & $46, \mathrm{XX}, \mathrm{t}(5 ; 12)$ \\
$(\mathrm{q} 13 ; \mathrm{q} 24)$ & $(\mathrm{q} 13 ; \mathrm{q} 24) \quad$ (Case 9) \\
$47, \mathrm{XX},+21$ & $46, \mathrm{XY} / 46, \mathrm{XY}, \mathrm{t}(8 ; 11)$ & $46, \mathrm{XX}$ \\
& $(\mathrm{q} 24 ; \mathrm{q} 13) \quad($ Case 10$)$ & \\
\hline
\end{tabular}

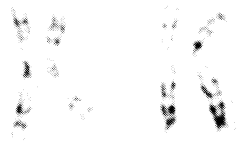

1

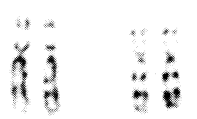

67

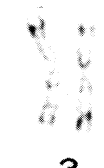

3
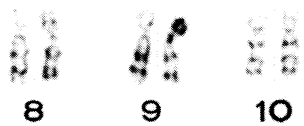

10
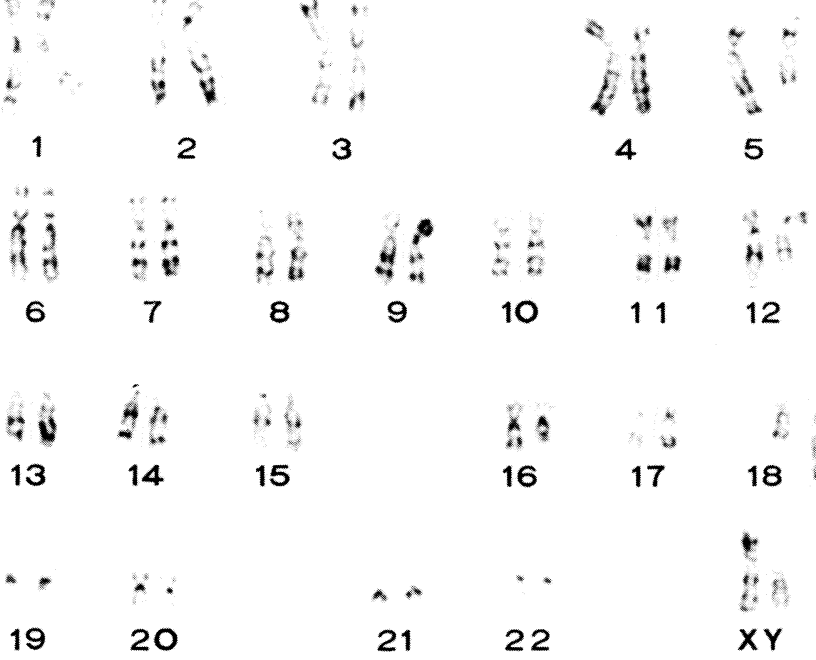

Fig. 10. Karyotype of Case 8 .

$46, \mathrm{XY}, \mathrm{t}(5 ; 18)(\mathrm{q} 15 ; \mathrm{q} 22)$

The relationship between offspring with congenital chromosomal abnormalities and the parents' karyotype

Table 4 summarizes the findings concerning offspring with congenital defects and their parents' karyotype. It was found that one carrier (Case 8) was the father of a stillborn fetus with unbalanced translocation showing $3: 1$ segregation (Fig. 10). Another parent (Case 9) of a stillborn fetus which had 21-trisomy and chromosomal translocation was found to be a carrier of a similar translocation (Fig. 11). One parent (Case 10) of a free 21-trisomy child was found to be a mosaic of a normal karyotype and balanced translocation (Fig. 12).

The outcome of pregnancies of the balanced translocation carriers

Table 5 presents the outcomes of the 31 pregnancies of the 10 balanced translocation carriers (Cases 1-10). Ten of the offspring had normal phenotypes $(32 \%)$, three of which were found to be balanced translocation carriers. Five of 


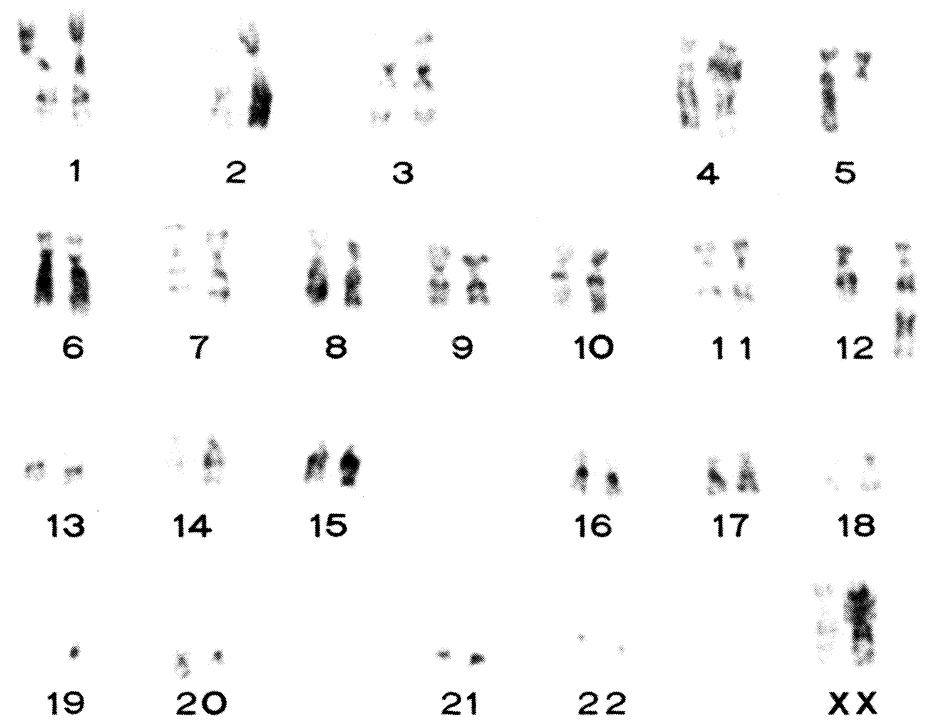

Fig. 11. Karyotype of Case 9 .

$46, \mathrm{XX}, \mathrm{t}(5 ; 12)(\mathrm{q} 13 ; \mathrm{q} 24)$
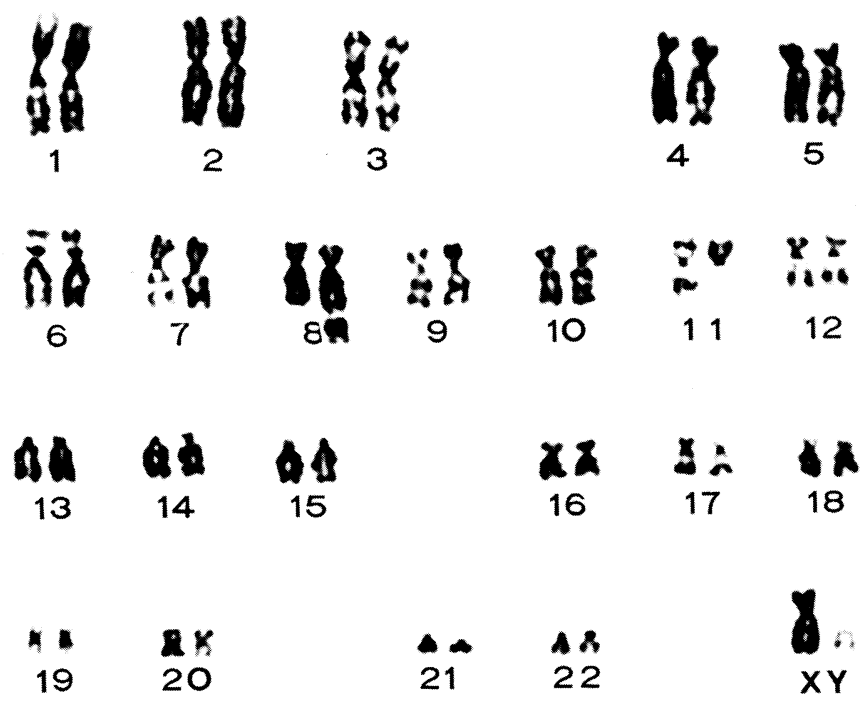

Fig. 12. Karyotype of Case 10.

$46, \mathrm{XY}, \mathrm{t}(8 ; 11)(\mathrm{q} 24 ; \mathrm{q} 13)$

the offspring $(16 \%)$ were born with chromosomal abnormalities and $16(52 \%)$ were spontaneously aborted. 
TABLE 5. Pregnancy outcome in parents with chromosome translocation

\begin{tabular}{|c|c|c|c|c|c|c|}
\hline $\begin{array}{l}\text { Case } \\
\text { No. }\end{array}$ & Karyotype & $\begin{array}{l}\text { Liveborn } \\
\text { without } \\
\text { anomalies }\end{array}$ & $\begin{array}{l}\text { Liveborn } \\
\text { with } \\
\text { anomalies }\end{array}$ & $\begin{array}{l}\text { Stillborn } \\
\text { with } \\
\text { anomalies }\end{array}$ & $\begin{array}{l}\text { Spontaneous } \\
\text { abortions }\end{array}$ & Total \\
\hline 1 & $\begin{array}{l}45, \mathrm{XX},-13,-14 \\
\quad+\mathrm{t}(13 \mathrm{q} 14 \mathrm{q})\end{array}$ & 0 & 0 & 0 & 2 & 2 \\
\hline 2 & $\begin{array}{l}45, \mathrm{XX},-13,-22 \\
\quad+\mathrm{t}(13 \mathrm{q} 22 \mathrm{q})\end{array}$ & 1 & 0 & 0 & 2 & 3 \\
\hline 3 & $\begin{array}{l}45, \mathrm{XX},-14,-21 \\
\quad+\mathrm{t}(14 \mathrm{q} 21 \mathrm{q})\end{array}$ & $1^{*}$ & $1^{a}$ & 0 & 5 & 7 \\
\hline 4 & $\begin{array}{l}45, \mathrm{XX},-21,-21, \\
\quad+\mathrm{t}(21 \mathrm{q} 21 \mathrm{q})\end{array}$ & 0 & 0 & 0 & 3 & 3 \\
\hline 5 & $\begin{array}{l}\text { 46, XX, t(14; ; 15) } \\
\quad(\mathrm{q} 24 ; \mathrm{q} 24)\end{array}$ & $1^{*}$ & 0 & 0 & 3 & 4 \\
\hline 6 & $\begin{array}{l}45, X Y,-13,-14 \\
\quad+\mathrm{t}(13 \mathrm{q} 14 \mathrm{q})\end{array}$ & $2(1) \dagger$ & 0 & 0 & 0 & 2 \\
\hline 7 & $\begin{array}{l}46, \mathrm{XY}, \mathrm{t}(14 ; 15) \\
\quad(\mathrm{q} 24 ; \mathrm{q} 24)\end{array}$ & $2(1) \dagger$ & $1^{b}$ & 0 & 0 & 3 \\
\hline 8 & $\begin{array}{l}\text { 46, XY, t( } 5 ; 18) \\
\quad(\mathrm{q} 15 ; \mathrm{q} 22)\end{array}$ & $1^{*}$ & 0 & $1^{e}$ & 1 & 3 \\
\hline 9 & $\begin{array}{l}\text { 46, XX, t(5;12) } \\
\quad(\mathrm{q} 13 ; \mathrm{q} 24)\end{array}$ & $1^{*}(1) \dagger$ & $1^{c}$ & 0 & 0 & 2 \\
\hline 10 & $\begin{array}{l}46, \mathrm{XY} / 46, \mathrm{XY} \\
\mathrm{t}(8 ; 11) \\
(\mathrm{q} 24 ; \mathrm{q} 13)\end{array}$ & $1^{*}$ & $1^{d}$ & 0 & 0 & 2 \\
\hline & Total & $\begin{array}{c}10(3) \\
(32 \%)\end{array}$ & \multicolumn{2}{|c|}{$(16 \%)$} & $16(52 \%)$ & 31 \\
\hline
\end{tabular}

* Prenatal diagnoses.

$\uparrow$ Number of balanced translocation cases in parenthesis.

a $46, \mathrm{XY},-14,+\mathrm{t}(14 \mathrm{q} 2 \mathrm{lq})$

b $46, \mathrm{XX}$, der. (15) t(14;15) (q24; q24)

c $47, \mathrm{XY},+21, \mathrm{t}(5 ; 12)(\mathrm{q} 13 ; \mathrm{q} 24)$

d $47, \mathrm{XY},+21$

e $47, \mathrm{XX},+18, \mathrm{t}(5 ; 18)(\mathrm{q} 15 ; \mathrm{q} 22)$

\section{Discussion}

In recent years, there have been frequent reports of the incidence of translocation carriers among couples experiencing recurrent abortions (Table 6). Taking these statistics together, $4.5 \%(6.1 \%$ for the females, $2.9 \%$ for the males $)$ of the individuals examined were found to be translocation carriers. In the present study we found an incidence of $7.1 \%$, all of the translocation carriers being female.

In light of the fact that the incidence of balanced translocation carriers in population studies is quite low $(0.3 \%)$, the incidence found among those experiencing spontaneous abortions may suggest a possible causal relationship between recurrent abortion and the translocation condition. 
TABLE 6. Frequency of balanced translocation carriers among parents with recurrent abortions

\begin{tabular}{lcccr}
\hline \multirow{2}{*}{ Reference } & \multicolumn{2}{c}{ Translocations detected } & Total & $\begin{array}{c}\text { Incidence } \\
\text { (\%) }\end{array}$ \\
\cline { 2 - 3 } & Wife & Husband & & 4.0 \\
\hline Kim et al. (1975) & $4 / 50$ & $0 / 50$ & $4 / 100$ & 4.1 \\
Schmidt et al. (1976) & $2 / 39$ & $1 / 35$ & $3 / 74$ & 3.2 \\
Tsenghi et al. (1976) & $1 / 77$ & $4 / 77$ & $5 / 154$ & 12.5 \\
Stenchever et al. (1977) & $6 / 28$ & $1 / 28$ & $7 / 56$ & 5.5 \\
Byrd et al. (1977) & $4 / 55$ & $2 / 55$ & $6 / 110$ & 7.4 \\
Mennuti et al. (1978) & $1 / 34$ & $4 / 34$ & $5 / 68$ & 5.5 \\
Tho et al. (1979) & $9 / 100$ & $2 / 100$ & $11 / 200$ & 0.0 \\
Genest (1979) & $0 / 51$ & $0 / 51$ & $0 / 102$ & 4.2 \\
Matton et al. (1980) & $4 / 96$ & $4 / 96$ & $8 / 192$ & 50.0 \\
Wisniewski et al. (1980) & $5 / 6$ & $1 / 6$ & $6 / 12$ & 9.3 \\
Antich et al. (1980) & $4 / 32$ & $2 / 32$ & $6 / 64$ & 3.9 \\
Subrt (1980) & $6 / 115$ & $3 / 115$ & $9 / 230$ & 2.0 \\
Michels et al. (1982) & $6 / 200$ & $2 / 200$ & $8 / 400$ & 4.0 \\
Davis et al. (1982) & $5 / 100$ & $3 / 100$ & $8 / 200$ & 7.1 \\
Present report & $5 / 35$ & $0 / 35$ & $5 / 70$ & $(4.5 \%)$ \\
Total & $62 / 1,018$ & $29 / 1,014$ & $91 / 2,032$ & \\
& $(6.1 \%)$ & $(2.9 \%)$ & $(1 \%)$ & \\
\hline
\end{tabular}

All parents had a history of two or more spontaneous abortions and with or without stillborn or anomalous liveborn infant.

All studies used the banding technique.

In the case of the female carriers, normally only one ovum matures each month, so that if the ovum is an unbalanced translocation gamete, then its fertilization will lead to the production of an abnormal zygote and most frequently to spontaneous abortion; only infrequently will offspring with congenital abnormalities survive.

In the case of male carriers, however, millions of sperms are released by every ejaculation, so that even when unbalanced translocation gametes are present, they will only infrequently fertilize the ovum and do not often cause the production of abnormal zygotes. This difference is thought to be the underlying factor which results in the higher incidence of female carriers detected than male carriers.

There is of course still the possibility of offspring with balanced or unbalanced translocations in which spontaneous abortions were caused by the male carrier, such as found in our Cases 6, 7, 8 and 10 (Table 5). Since translocation characteristics can be transmitted from father to offspring, it is essential that chromosome study of the male in cases of recurrent spontaneous abortion also be undertaken.

Habitual abortion has been defined as three or more incidents of abortion and only those couples who are habitual aborters are generally thought to be 
suitable for chromosome analysis. In the present study, however, we have found that $14 \%$ of the couples who had experienced only 2 spontaneous abortions included translocation carriers. It is, therefore, desirable that all couples with two or more spontaneous abortions undergo chromosome analysis.

Both on theoretical grounds and from clinical experience it is known that carriers of translocations of homologous chromosomes (Case 4) (Table 5) will produce $100 \%$ abnormal fetuses and that normal offspring cannot be expected. With regard to the children of carriers of translocations on non-homologous chromosomes, it is expected theoretically that the ratio of normal offspring (including translocation carriers) to abnormal offspring will be $1: 2$, provided that chromosomal crossing-over is disregarded. If all abortuses were abnormal offspring, the ratio of normal to abnormal fetuses in the present research would be $1: 1.8$ - or quite close to the theoretical value (excluding only Case 4 from Table 5). It should be noted, however, that the carriers of the present study were those with recurrent spontaneous abortion or the parents of congenitally abnormal offspring and their families-i.e., only those lineages which showed clinical symptoms. Consequently, it is thought that the pregnancy outcome showed a tendency which is less favorable than that in the general population. It remains unclear what the pregnancy outcome of symptomless translocation carriers might be. Particularly in light of the fact that chromosomal screening tests of newborn infants have been carried out on recent years at various institutions, it is worthwhile to investigate prospectively the outcome of pregnancies of the children of detected translocation carriers.

As noted above, analysis of the 31 pregnancy outcomes of the carriers in our study (Table 5) showed two 21-trisomy offspring (Cases 9 and 10); indicating an incidence of $6 \%$-which is nearly 50 -fold higher than the incidence of 21-trisomy in Japan $(0.09-0.13 \%)$. This extremely high incidence of 21 -trisomy is thought to indicate that, in addition to unbalanced translocations, the offspring of translocation carriers exhibit a chromosomal trisomy which is unrelated to the parental translocated chromosome. At the same time, this finding suggests that the parent of offspring with free 21-trisomy (which is thought to be a non-genetic condition) is a translocation carrier possibly.

\section{References}

1) Antich, J., Clusellas, N., Twose, A. \& Godo, R.M. (1980) Chromosomal abnormalities in parents in cases of reproductive failure. Clin. Genet., 17, 52.

2) Byrd, J.R., Askew, D.E. \& McDonough, P.G. (1977) Cytogenetic findings in fifty-five couples with recurrent fetal wastage. Fertil. Steril., 28, 246-250.

3) Davis, J.R., Weinstein, L., Veomett, I.C., Shenker, L., Giles, H.R. \& Hauck, L. (1982) Balanced translocation karyotypes in patients with repetitive abortion. Amer. J. Obstet. Gynecol., 144, 229-233.

4) Genest, P. (1979) Chromosome variants and abnormalities detected in 51 married couples with repeated spontaneous abortions. Clin. Genet., 16, 387-389. 
5) Jacobs, P.A., Franckiewicz, A. \& Law, P. (1972) Incidence and mutation rates of structural rearrangements of the autosomes in man. Ann. hum. Genet., 35, 301-319.

6) Kajii, T. (1979) Chromosomal study in spontaneous abortuses. Perinat. Med., 9, 1449-1454. (Japanese)

7) Kim, H.J., Hsu, L.Y.F., Paciuc, S., Christian, S., Quintanta, A. \& Hirschhorn, K. (1975) Cytogenetics of fetal wastage. New Engl. J. Med., 293, 844-847.

8) Matton, M., Verschraegen-Sape, M.R., De Bie, S. \& Van der Wijagaert, J. (1980) Incidence of $\mathrm{T}$ carriers amongst couples with repetitive abortion, after exclusion of other etiology. Clin. Genet., 17, 78.

9) Mennuti, M.T., Jingeleski, S., Schwarz, R.H. \& Mellman, W.J. (1978) An evaluation of cytogenetic analysis as a primary tool in the assessment of recurrent pregnancy wastage. Obstet. Gynecol., 52, 308-313.

10) Michels, V.V., Medrano, C., Venne, V. \& Riccardi, V.M. (1982) Chromosome translocations in couples with multiple spontaneous abortions. Amer. J. hum. Genet., 34, 507-513.

11) Schmidt, R., Nitowsky, H.M. \& Dar, H. (1976) Cytogenetic studies in reproductive loss. J. Amer. med. Ass., 236, 369-373.

12) Stenchever, M.A., Parks, K.J., Daines, T.L., Allen, M.A. \& Stenchever, M.R. (1977) Cytogenetics of habitual abortion and other reproductive wastage. Amer. J. Obstet. Gynecol., 127, 143-150.

13) Subrt, I. (1980) Reciprocal translocation with special reference to reproductive failure. Hum. Genet., 55, 303-307.

14) Tho, P.T., Byrd, J.R. \& McDonough, P.G. (1979) Etiologies and subsequent reproductive performance of 100 couples with recurrent abortion. Fertil. Steril., 32, 389395.

15) Tsenghi, C., Metaxotou-Stavridaki, C., Stratakibenetou, M., Kalpini-Mavrou, A. \& Matsaniotis, N. (1976) Chromosome studies in couples with repeated abortions. Obstet. Gynecol., 47, 463-468.

16) Wisniewski, L., Lech, H., Krajewska-Walasek, H. \& Niezabitowska, A. (1980) Balanced translocations on parents with reproductive failure. Clin. Genet., 17, 94. 